\title{
MEMPERKIRAKAN KEDALAM RETAK PADA BETON MENGGUNAKAN GELOMBANG ULTRASONIK
}

\author{
Dewi Linggasari ${ }^{1}$ \\ ${ }^{1}$ Program Studi Sarjana Teknik Sipil, Universitas Tarumanagara Jakarta \\ Email:dewil@ft.untar.ac.id
}

Masuk: 08-05-2019, revisi: 06-08-2019, diterima untuk diterbitkan: 08-08-2019

\begin{abstract}
ABSTRAK
Tulisan ini mendiskusikan penggunaan gelombang ultrasonik untuk memperkirakan kedalaman retak terbuka. Teknik yang digunakan sangat berguna dalam pekerjaan di lapangan. Metode pengukuran menggunakan dua metode acuan yaitu standard BS 1881 bagian 203 sebagai metode 1 dan manual buku pada alat PUNDIT CNS Electronics sebagai metode ke 2, dengan gambaran persamaan matematika untuk menentukan kedalaman retak terbuka. Gelombang ultrasonik bekerja didasarkan pada pengukuran waktu tempuh gelombang ultrasonik yang menjalar dalam struktur beton. Gelombang ultrasonik disalurkan dari pengirim yang ditempatkan dipermukaan beton melalui material beton menuju penerima dan waktu tempuh gelombang tersebut diukur oleh Read-Out unit dalam mikro detik. Sejumlah balok uji disiapkan dengan penandaan arah keretakan untuk pengukuran. Hasil pengujian menunjukkan kedua metode yang digunakan untuk mengukur kedalaman keretakan memiliki kesesuain hasil antar satu terhadap yang lainnya.
\end{abstract}

Kata Kunci: Ultrasonik; kedalaman; keretakan; pengirim; penerima

\begin{abstract}
This paper discusses the use of ultrasonic waves to estimate the depth of open cracks. The technique used is very useful in work in the field. The measurement method uses two reference methods namely standard BS 1881 section 203 as method 1 and the book manual on the PUNDIT CNS Electronics tool as the second method, with an overview of mathematical equations to determine the depth of open cracks. Ultrasonic waves work based on measurements of the travel time of ultrasonic waves that propagate in concrete structures. Ultrasonic waves are transmitted from the sender placed on the concrete surface through concrete material to the receiver and the wave travel time is measured by the Read-Out unit in micro seconds. A number of test beams were prepared by marking the direction of the crack for measurement. The test results show that the two methods used to measure the depth of the crack have the suitability of the results between one another.
\end{abstract}

Keywords: Ultrasonic; depth; crack; sender; receiver

\section{PENDAHULUAN}

Keretakan pada beton dapat dibedakan menjadi retak struktural maupun non - struktural. Keretakan struktural terjadi karena adanya kesalahan dalam perencanaan atau beban yang melebihi kapasitas, sedangkan retakan non-struktural sebagian besar terjadi karena adanya proses kimia fisik pada beton pada fase awal umur beton. Pada umumnya retakan non-struktural tidak langsung mengakibatkan melemahnya struktur bangunan. Kedalaman dan lebar retak pada sebuah beton dapat diukur menggunakan gelombang ultrasonik. Gelombang ultrasonik bekerja didasarkan pada pengukuran waktu tempuh gelombang ultrasonik yang menjalar dalam struktur beton. 
Kedua pengirim ditempatkan secara indirect, karena jarak antara kedua pengirim ini telah diketahui, maka kecepatan gelombang ultrasonik dalam material beton dapat dihitung, yaitu jarak antar pengirim dibagi dengan waktu tempuh (ASTM C597). Kecepatan rambat gelombang adalah merupakan fungsi dari kepadatan material, maka dengan diketahuinya cepat rambat gelombang ultrasonik di dalam beton, kecepatan tersebut dapat dikorelasikan ke nilai kedalaman retak terbuka, berdasarkan grafik empiris hubungan antara waktu tempuh dengan jarak rambat gelombang (Shiotani dan Angelis, 2007) .

BS 1881 bagian 203, menjelaskan dengan menggunakan persamaan matematika yang dituliskan pada persamaan 1 untuk mengukur kedalaman retak terbuka seperti ditunjukkan pada Gambar 1 . Pada gambar tersebut kedalaman retak terbuka di lambangkan dengan huruf $h$, sedangkan jarak antar pengirim diposisikan dengan huruf $b$.

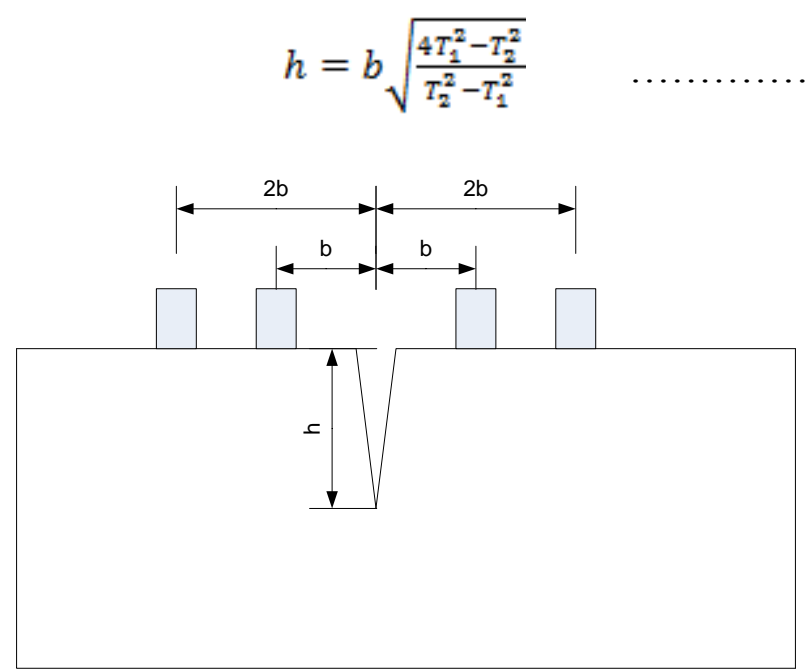

Gambar 1. Pengukuran kedalaman retak metode 1 menurut BS 1881: bagian 203

Keretakan sendiri dapat diukur dari lebarnya, panjangnya dan pola umumnya, namun biasanya lebar retak ini sulit diukur karena bentuknya yang tidak teratur (Wibowo dkk., 2014).

Selain itu ada retakan yang disebut retak mikro, retak ini terjadi pada fase pengerasan beton dimana retakan jenis ini akan sulit dideteksi karena terlalu kecil. Retakan ini hanya dapat dideteksi menggunakan alat Ultrasonic Flaw Detector yang dapat mengetahui keretakan hingga ukuran mikro.

Lebar-sempit, panjang-pendek dan kedalaman keretakan dipengaruhi oleh banyak faktor diantaranya adalah penyebab timbulnya retak, umur retak dan sebagainya. Keretakan yang muncul pada elemen struktur baik itu balok, kolom ataupun pelat harus segera ditangani. Biasanya penangan yang akan dilakukan didahului dengan investigasi terhadap keretakan itu sendiri yaitu kedalaman, lebar dan panjang keretakan. Pengukuran lebar dan panjang retak sangat mudah untuk dilakukan karena secara visual sangat jelas, namun penngukuran kedalaman retak sangat sulit dilakukan karena tidak terlihat secara nyata, ditambah lagi bila keretakan yang terjadi sangat kecil atau diistilahkan dengan sebutan keretakan mikro (Mahdi dkk, 2011). Diperlukan ketelitian, kehati-hatian dan ketekunan dalam menentukan kedalaman retak tersebut, mengingat kedalaman retak sangat menentukan penanganan yang akan dilakukan terhadap elemen struktur tersebut. 
Beberapa metode telah dikembangkan untuk menentukan kedalaman keretakan yang terjadi pada elemen struktur. Salah satunya BS 1881 bagian 203 seperti ditunjukkan pada persamaan 1. Pada tulisan ini dibandingkan dua metode pengukuran kedalaman retak yang terjadi pada elemen struktur yaitu seperti yang dituliskan pada persamaan 1 dengan metode yang disediakan pada manual peralatan seperti ditunjukkan pada persamaan 2 , huruf $\mathrm{h}$ melambangkan kedalam keretakan, $\mathrm{T}_{1}$ dan $\mathrm{T}_{2}$ menyatakan waktu tempuh, sedangkan $\mathrm{L}$ melambangkan jarak awal antara pengirim dengan keretakan (CNS Electronics)

$$
\mathrm{h}=\frac{\mathrm{L}}{2}\left(\frac{\mathrm{T}_{2}}{\mathrm{~T}_{1}}-\frac{\mathrm{T}_{1}}{\mathrm{~T}_{2}}\right)
$$

Tujuan dari penelitian yang dikerjakan ini adalah membandingkan dua metode pengukuran kedalaman keretakan pada persamaan 1 dan persamaan 2, dengan tujuan untuk mendapatkan tingkat akurasi yang lebih baik dalam memperkirakan kedalaman keretakan, sehingga bermanfaat digunakan dalam pengambilan keputusan penanganan terhadap elemen struktur yang mengalami keretakan.

\section{METODOLOGI}

Data penelitian dikumpulkan melalui pengukuran pada balok yang mengalami keretakan pada sebuah pusat perbelanjaan di daerah Tangerang. Pada permukaan balok dilakukan pembersihan dari debu yang menempel, penandaan jarak, dan pengukuran. Pengukuran metode 1 dilakukan seperti pada Gambar 1 dan pengukuran metode 2 dilakukan seperti pada Gambar 2.

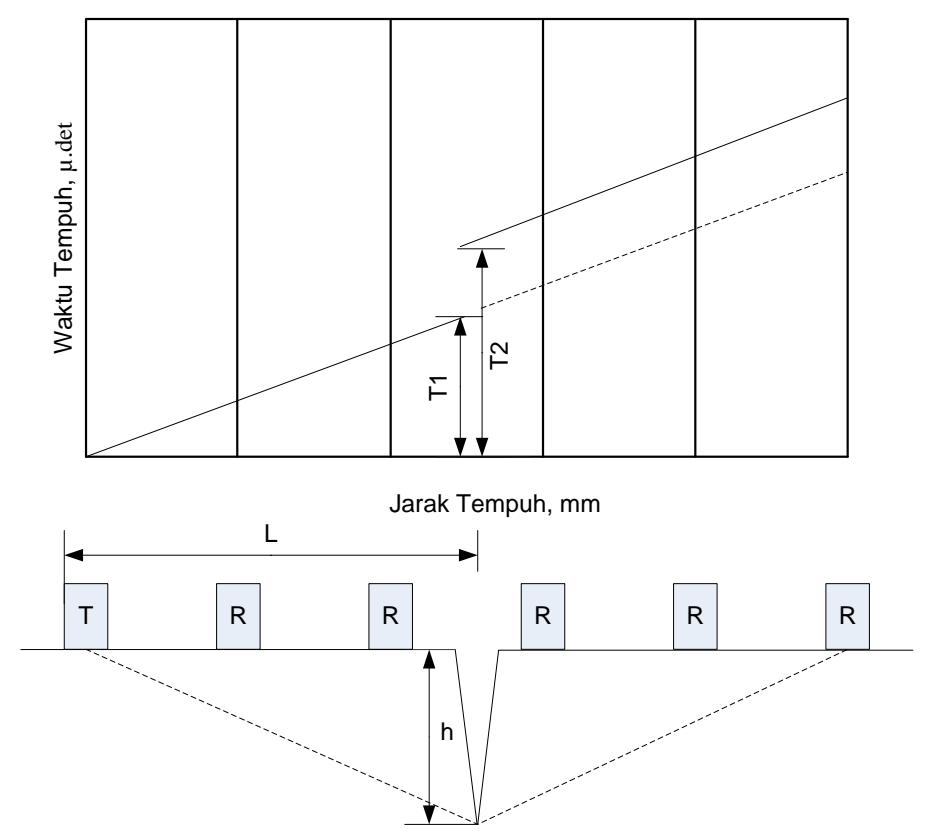

Gambar 2. Pengukuran kedalam retak dengan metode 2

\section{HASIL DAN DISKUSI}

Berdasarkan pengukuran yang dilakukan terhadapat seluruh benda uji, data yang berhasil dikumpulkan disajikan pada Tabel 1 dan Tabe1 2 sebagai berikut: 
Tabel 1. Jarak dan waktu tempuh pulsa pada balok uji metode 1

\begin{tabular}{|c|c|c|c|c|c|c|c|}
\hline No. & Balok & $\begin{array}{c}\mathrm{T}_{1} \\
\mu . \mathrm{det}\end{array}$ & $\begin{array}{c}\mathrm{T}_{2} \\
\mu . \operatorname{det}\end{array}$ & No. & Balok & $\begin{array}{c}\mathrm{T}_{1} \\
\mu . \mathrm{det}\end{array}$ & $\begin{array}{c}\mathrm{T}_{2} \\
\mu . \operatorname{det}\end{array}$ \\
\hline 1 & $\begin{array}{c}\text { Balok As UV/34 } \\
680 \mathrm{~mm} \mathrm{X} 420 \mathrm{~mm}\end{array}$ & 123.5 & 163.4 & 6 & $\begin{array}{c}\text { Balok As DD-EE/45 } \\
670 \mathrm{~mm} \text { X } 410 \mathrm{~mm}\end{array}$ & 122.9 & 168.8 \\
\hline 2 & $\begin{array}{c}\text { Balok As NP/38 } \\
670 \mathrm{~mm} \mathrm{X} 410 \mathrm{~mm}\end{array}$ & 127.2 & 198.1 & 7 & $\begin{array}{c}\text { Balok As E/47-48 } \\
680 \mathrm{~mm} \text { X } 420 \mathrm{~mm}\end{array}$ & 112.3 & 172.3 \\
\hline 3 & $\begin{array}{l}\text { Balok As EE/33-34 } \\
680 \mathrm{~mm} \mathrm{X} 420 \mathrm{~mm} \\
\end{array}$ & 116.3 & 172.4 & 8 & $\begin{array}{c}\text { Balok As HH-JJ/48-49 } \\
400 \mathrm{~mm} \mathrm{X} 250 \mathrm{~mm} \\
\end{array}$ & 127.1 & 153.2 \\
\hline 4 & $\begin{array}{l}\text { Balok As EE/31-32 } \\
700 \mathrm{~mm} \mathrm{X} 400 \mathrm{~mm}\end{array}$ & 113 & 201.3 & 9 & $\begin{array}{c}\text { Balok As JJ/48-49 } \\
700 \mathrm{~mm} \text { X } 400 \mathrm{~mm}\end{array}$ & 118.6 & 195.6 \\
\hline 5 & $\begin{array}{l}\text { Balok As EE/30-31 } \\
690 \mathrm{~mm} \mathrm{X} 400 \mathrm{~mm}\end{array}$ & 121.3 & 202.7 & 10 & $\begin{array}{l}\text { Balok As JJ/47-48 } \\
700 \mathrm{~mm} \mathrm{X} 400 \mathrm{~mm}\end{array}$ & 122.1 & 195.6 \\
\hline
\end{tabular}

Tabel 2. Jarak dan waktu tempuh pulsa pada balok uji metode 2

\begin{tabular}{|c|c|c|c|c|c|c|c|}
\hline \multicolumn{2}{|c|}{$\begin{array}{c}\text { Balok As UV/34 } \\
680 \mathrm{~mm} \text { X } 420 \mathrm{~mm}\end{array}$} & \multicolumn{2}{|c|}{$\begin{array}{c}\text { Balok As NP/38 } \\
670 \mathrm{~mm} \text { X } 410 \mathrm{~mm}\end{array}$} & \multicolumn{2}{|c|}{$\begin{array}{l}\text { Balok As EE/33-34 } \\
680 \mathrm{~mm} \text { X } 420 \mathrm{~mm}\end{array}$} & \multicolumn{2}{|c|}{$\begin{array}{l}\text { Balok As EE/31-32 } \\
700 \mathrm{~mm} \text { X } 400 \mathrm{~mm}\end{array}$} \\
\hline $\begin{array}{c}\text { Jarak } \\
\text { mm }\end{array}$ & $\begin{array}{l}\text { Waktu } \\
\mu . d e t\end{array}$ & $\begin{array}{c}\text { Jarak } \\
\text { mm }\end{array}$ & $\begin{array}{l}\text { Waktu } \\
\mu . d e t\end{array}$ & $\begin{array}{c}\text { Jarak } \\
\mathrm{mm}\end{array}$ & $\begin{array}{l}\text { Waktu } \\
\mu . d e t\end{array}$ & $\begin{array}{c}\text { Jarak } \\
\mathrm{mm}\end{array}$ & $\begin{array}{l}\text { Waktu } \\
\mu . \text { det }\end{array}$ \\
\hline 0 & 0 & 0 & 0 & 0 & 0 & 0 & 0 \\
\hline 100 & 51,9 & 100 & 37,5 & 100 & 40,9 & 100 & 43,4 \\
\hline 200 & 97,6 & 200 & 78,4 & 200 & 81,7 & 200 & 83,6 \\
\hline 300 & 260,0 & 300 & 163,8 & 300 & 188,1 & 300 & 155,1 \\
\hline 400 & 310,9 & 400 & 199,9 & 400 & 229,3 & 400 & 193,5 \\
\hline 500 & 358,3 & 500 & 238,7 & 500 & 271,6 & 500 & 232,0 \\
\hline \multicolumn{2}{|c|}{$\begin{array}{l}\text { Balok As EE/30-31 } \\
690 \mathrm{~mm} \text { X } 400 \mathrm{~mm}\end{array}$} & \multicolumn{2}{|c|}{$\begin{array}{c}\text { Balok As DD-EE/45 } \\
670 \mathrm{~mm} \text { X } 410 \mathrm{~mm}\end{array}$} & \multicolumn{2}{|c|}{$\begin{array}{l}\text { Balok As E/47-48 } \\
680 \mathrm{~mm} \text { X } 420 \mathrm{~mm}\end{array}$} & \multicolumn{2}{|c|}{$\begin{array}{c}\text { Balok As HH-JJ/48-49 } \\
400 \mathrm{~mm} \mathrm{X} 250 \mathrm{~mm}\end{array}$} \\
\hline 0 & 0 & 0 & 0 & 0 & 0 & 0 & 0 \\
\hline 100 & 28,8 & 100 & 37,2 & 100 & 31,5 & 100 & 43,4 \\
\hline 200 & 56,7 & 200 & 72,3 & 200 & 61,9 & 200 & 83,6 \\
\hline 300 & 114,6 & 300 & 181,2 & 300 & 135,7 & 300 & 155,1 \\
\hline 400 & 142,0 & 400 & 217,6 & 400 & 166,9 & 400 & 193,5 \\
\hline 500 & 171,1 & 500 & 254,4 & 500 & 200,4 & 500 & 232,0 \\
\hline \multicolumn{2}{|c|}{$\begin{array}{l}\text { Balok As EE/30-31 } \\
690 \mathrm{~mm} \text { X } 400 \mathrm{~mm}\end{array}$} & \multicolumn{2}{|c|}{$\begin{array}{c}\text { Balok As DD-EE/45 } \\
670 \mathrm{~mm} \text { X } 410 \mathrm{~mm}\end{array}$} & & & & \\
\hline 0 & 0 & 0 & 0 & & & & \\
\hline 100 & 28,8 & 100 & 37,2 & & & & \\
\hline 200 & 56,7 & 200 & 72,3 & & & & \\
\hline 300 & 114,6 & 300 & 181,2 & & & & \\
\hline 400 & 142,0 & 400 & 217,6 & & & & \\
\hline 500 & 171,1 & 500 & 254,4 & & & & \\
\hline
\end{tabular}


Data pada Tabel 2 dibuat grafik seperti tampak pada gambar 3 untuk menentukan nilai $\mathrm{T}_{1}$ dan $\mathrm{T}_{2}$ berdasarkan metode 2 , nilai $\mathrm{T}_{1}, \mathrm{~T}_{2}$ ini di sajikan pada tabel 3 berikut ini.

Tabel 3. Nilai $\mathrm{T}_{1}$ dan $\mathrm{T}_{2}$ pada metode 2

\begin{tabular}{|c|c|c|c|c|c|c|c|}
\hline No. & Balok & $\begin{array}{c}\mathrm{T}_{1} \\
\mu . \operatorname{det}\end{array}$ & $\begin{array}{c}\mathrm{T}_{2} \\
\mu . \operatorname{det}\end{array}$ & No. & Balok & $\begin{array}{c}\mathrm{T}_{1} \\
\mu . \operatorname{det}\end{array}$ & $\begin{array}{c}\mathrm{T}_{2} \\
\mu . \operatorname{det}\end{array}$ \\
\hline 1 & $\begin{array}{c}\text { Balok As UV/34 } \\
680 \mathrm{~mm} \mathrm{X} 420 \mathrm{~mm}\end{array}$ & 124 & 236 & 6 & $\begin{array}{l}\text { Balok As DD-EE/45 } \\
670 \mathrm{~mm} \text { X } 410 \mathrm{~mm}\end{array}$ & 91 & 163 \\
\hline 2 & $\begin{array}{c}\text { Balok As NP/38 } \\
670 \mathrm{~mm} \mathrm{X} 410 \mathrm{~mm}\end{array}$ & 96 & 145 & 7 & $\begin{array}{c}\text { Balok As E/47-48 } \\
680 \mathrm{~mm} \text { X } 420 \mathrm{~mm}\end{array}$ & 78 & 120 \\
\hline 3 & $\begin{array}{l}\text { Balok As EE/33-34 } \\
680 \mathrm{~mm} \mathrm{X} 420 \mathrm{~mm}\end{array}$ & 103 & 168 & 8 & $\begin{array}{c}\text { Balok As HH-JJ/48-49 } \\
400 \mathrm{~mm} \mathrm{X} 250 \mathrm{~mm}\end{array}$ & 105 & 240 \\
\hline 4 & $\begin{array}{l}\text { Balok As EE/31-32 } \\
700 \mathrm{~mm} \mathrm{X} 400 \mathrm{~mm}\end{array}$ & 103 & 135 & 9 & $\begin{array}{c}\text { Balok As JJ/48-49 } \\
700 \mathrm{~mm} \text { X } 400 \mathrm{~mm}\end{array}$ & 101 & 140 \\
\hline 5 & $\begin{array}{l}\text { Balok As EE/30-31 } \\
690 \mathrm{~mm} \mathrm{X} 400 \mathrm{~mm}\end{array}$ & 71 & 100 & 10 & $\begin{array}{c}\text { Balok As JJ/47-48 } \\
700 \mathrm{~mm} \mathrm{X} 400 \mathrm{~mm}\end{array}$ & 90 & 135 \\
\hline
\end{tabular}

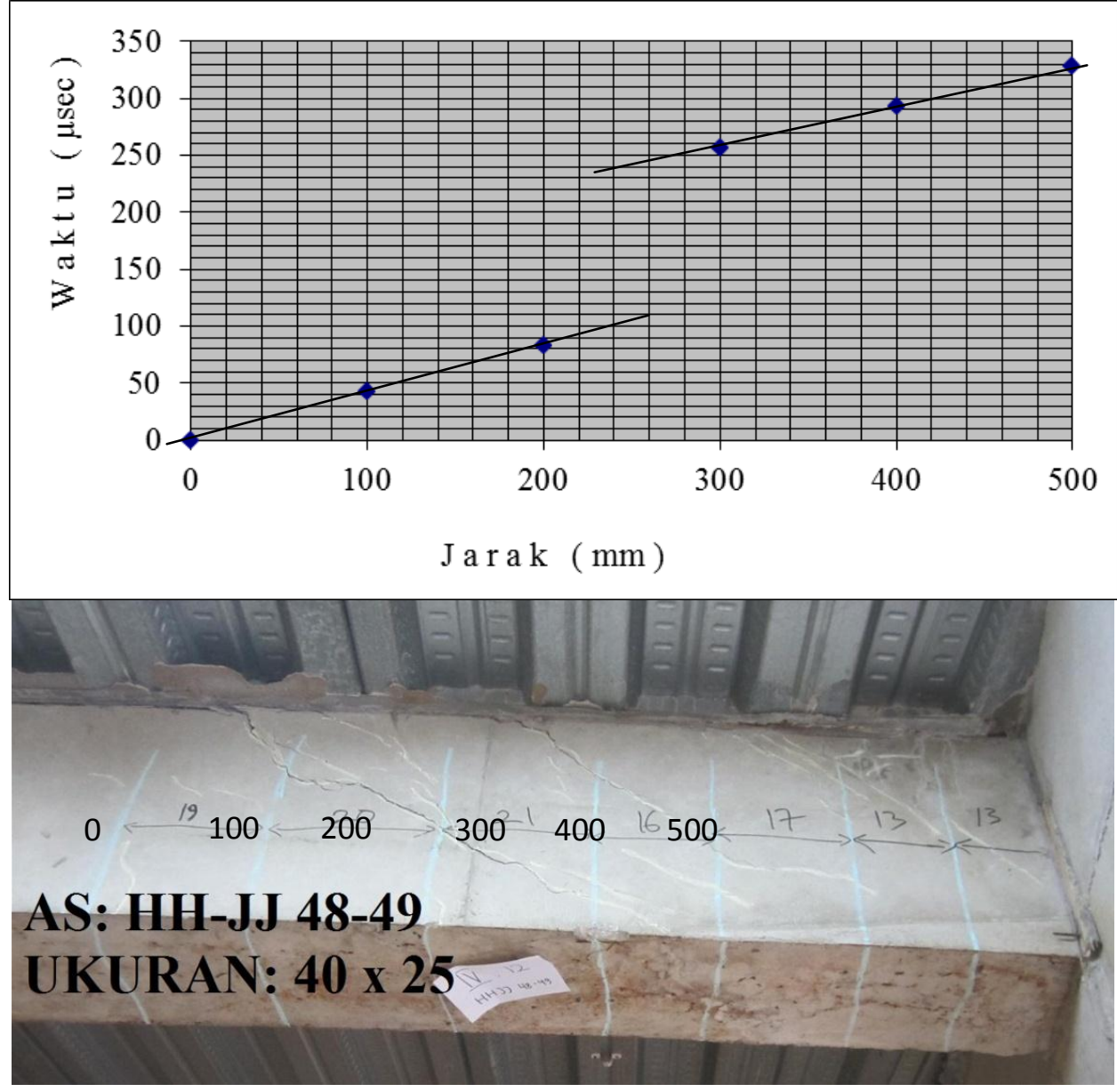

Gambar 3. Grafik hubungan jarak dan waktu tempuh sebelum dan sesudah keretakan pada balok AS HH-JJ/48-49 
Berdasarkan Tabel 1 dan Tabel 3 serta dengan menggunakan persamaan 1 dan persamaan 2 ditentukan kedalaman keretakan pada masing-masing balok seperti pada Tabel 4 berikut:

Tabel 4. Kedalaman keretakan balok berdasarkan metode 1 dan metode 2

\begin{tabular}{|c|c|c|c|c|}
\hline \multirow{2}{*}{ No. } & Balok & \multicolumn{2}{|c|}{ Kedalaman Keretakan, h (mm) } & Perbedaan Hasil \\
\cline { 3 - 4 } & $\begin{array}{c}\text { Metode } 1 \\
\mathrm{~b}=100,0 \mathrm{~mm}\end{array}$ & $\begin{array}{c}\text { Metode } 2 \\
\mathrm{~L}=250,0 \mathrm{~mm}\end{array}$ & $\begin{array}{c}\mathrm{mm} \\
\mathrm{mm}\end{array}$ \\
\hline 1 & $\begin{array}{c}\text { Balok As UV/34 } \\
680 \mathrm{~mm} \text { X 420 mm }\end{array}$ & 173 & 172 & 1 \\
\hline 2 & $\begin{array}{c}\text { Balok As NP/38 } \\
670 \mathrm{~mm} \text { X 410 mm }\end{array}$ & 105 & 106 & 1 \\
\hline 3 & $\begin{array}{c}\text { Balok As EE/33-34 } \\
680 \mathrm{~mm} \text { X 420 mm }\end{array}$ & 123 & 127 & 4 \\
\hline 4 & $\begin{array}{c}\text { Balok As EE/31-32 } \\
700 \mathrm{~mm} \text { X 400 mm }\end{array}$ & 62 & 68 & 5 \\
\hline 5 & $\begin{array}{c}\text { Balok As EE/30-31 } \\
690 \mathrm{~mm} \text { X 400 mm }\end{array}$ & 82 & 87 & 0 \\
\hline 6 & $\begin{array}{c}\text { Balok As DD-EE/45 } \\
670 \mathrm{~mm} \text { X 410 mm }\end{array}$ & 154 & 154 & 1 \\
\hline 7 & $\begin{array}{c}\text { Balok As E/47-48 } \\
680 \mathrm{~mm} \text { X 420 mm }\end{array}$ & 110 & 111 & 6 \\
\hline 8 & $\begin{array}{c}\text { Balok As HH-JJ/48-49 } \\
400 \mathrm{~mm} \text { X 250 mm }\end{array}$ & 237 & 231 & 3 \\
\hline 9 & $\begin{array}{c}\text { Balok As JJ/48-49 } \\
700 \mathrm{~mm} \mathrm{X} \mathrm{400} \mathrm{mm}\end{array}$ & 86 & 83 & 2 \\
\hline 10 & $\begin{array}{c}\text { Balok As JJ/47-48 } \\
700 \mathrm{~mm} \mathrm{X} \mathrm{400} \mathrm{mm}\end{array}$ & 96 & 94 & 4 \\
\hline
\end{tabular}

Tabel 4 memperlihatkan kedalaman keretakan yang terjadi pada balok menurut metode 1 dan metode 2. Perbedaan hasil pengukuran kedalaman keretakan oleh kedua metode tersebut tidak menunjukkan perbedaan yang signifikan $(1 \%-2 \%)$, sehingga kedua metode tersebut memiliki akurasi yang baik dalam memperkirakan kedalaman keretakan yang terjadi pada beton.

Kecepatan penjalaran gelombang ultrasonik pada beton dipengaruhi oleh banyak faktor, antara lain kelembaban beton, kebersihan permukaan beton dan kehalusan permukaan beton (Pinto, 2015). Apabila permukaan beton basah, kotor dan tidak rata maka waktu tempuh gelombang ultrasonik dari pengirim menuju reciver menjadi sangat lama, ini disebabkan dalam penjalarannya gelombang ultrasonik memerlukan zat perantara. Bila permukaan beton tersebut basah, kotor dan tidak rata akan menciptakan banyak rongga udara atau void di sepanjang aliran gelombang ultrasonik sehingga diperlukan waktu untuk berbelok menghindari void tersebut, sebagai akibatnya waktu tempuh menjadi lebih lambat. Dengan adanya gangguan-gangguan tersebut berakibat pada pembacaan waktu tempuh atau kecepatan rambat gelombang ultrasonik menjadi tidak akurat. Analisis tersebut tersebut menjadi dasar acuan prosedur yang benar dalam pengukuran kecepatan atau waktu tempuh gelombang ultrasonik. Diperlukan kepastian terhadap kondisi elemen struktur yang akan diuji terhadap tingkat kelembapan, kebersihan dan kerataan permukaan. 
Keretakan merupakan kejadian yang seringkali muncul pada beton, ada yang lebar maupun sempit, panjang atau pendek, teratur atau tidak, dalam atau tidak. Banyak faktor yang menyebabkan munculnya keretakan, antara lain perbedaan temperatur dalam beton, proses pengeringan, proses pembebanan dan laninnya. Pada banyak kasus, keretakan yang muncul pada permukaan beton tidak berpengaruh terhadap kemampuan beton dalam memikul beban, namun lebih banyak pengaruhnya pada keawetan beton yaitu intrusi bahan-bahan agresif kedalam beton yang dapat memicu korosi besi penulangan. Sehingga kedalaman keretakan sangat mementukan penanganan yang harus dilakukan pada elemen struktur yang mengalami keretakan.

\section{KESIMPULAN}

Berdasarkan diskusi tersebut diatas maka dapat diambil kesimpulan sebagai berikut:

1. Pengukuran kedalaman keretakan pada elemen struktur beton, dapat dilakukan dengan metode yang mengacu pada standard BS 1881 bagian 203 dan buku manual petunjuk penggunaan alat PUNDIT.

2. Kedua metode yang digunakan tidak menunjukkan perbedaan hasil kedalaman keretakan yang signifikan.

3. Dalam pengukuran waktu tempuh atau kecepatan rambat gelombang ultrasonik kondisi beton yang diuji harus kering, bersih dan rata.

4. Kedalaman keretaka yang terjadi pada beton berpengaruh pada metode perbaikan yang akan dilakukan pada elemen struktur tersebut.

5. Keretakan merupakan kejadian yang sering timbul pada elemen strukur sehingga diperlukan penanganan dan perencanaan yang tepat sebelum, saat dan setelah pengecoran.

\section{DAFTAR PUSTAKA}

BS 1881: Part 203, 1986 Measurement of Velocity of Ultrasonik Pulses in Concrete, BSI, U.K., 1986.

ASTM C 597 , 2009. Test for Pulse Velocity Through Concrete, ASTM, U.S.A.,

Pinto, Roberto C. A, Medeiros, Arthur, Padaratz, Ivo J., Andrade, Patricia B. 2015. Use of Ultrasound to Estimate Depth of Surface Opening Cracks in Concrete Structures, www.ndt.net/?id=9954

Shiotani, T. \& Aggelis, D.G. 2007. Determination of surface crack depth and repair effectiveness using Rayleigh waves, Research Institute of Technology, Tobishima Corporation, Noda-shi, Japan

Wibowo, Ari, Suseno, Hendro, Hasyim, M. Hamzah, Roland Martin, N. Christin Remayanti, K. Ardian Prima. 2014. Crack Depth Measurement Of Reinforced Concrete Beams Using $U P V$, Jurnal Rekayasa Sipil, Vol 8 No.1, 41-46.

Mahdi, Shariati; Ramli-Sulong, Nor Hafizah; K. H. Mohammad Mehdi Arabnejad; Shafigh, Payam; Sinaei, Hamid, 2011, Assessing The Strength Of Reinforced Concrete Structures Through Ultrasonik Pulse Velocity And Schmidt Rebound Hammer Tests, Scientific Research and Essays Vol. 6(1), pp. 213-22

CNS Electronics Ltd, Operating Instructions Pundit Plus Ultrasonik Instrument. 
